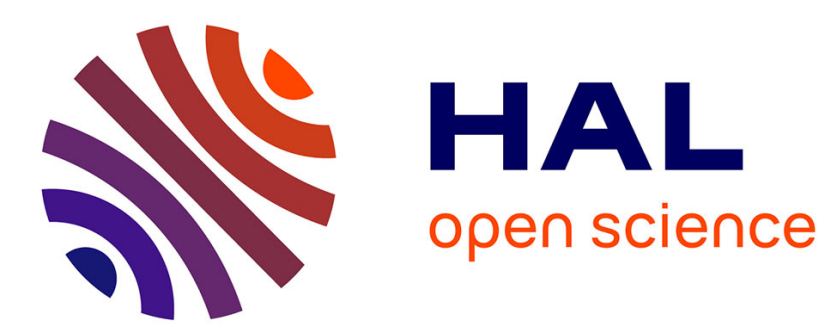

\title{
Small-scale trench in the North polar region of Mars: evolution of surface frost and ground ice concentration
}

Konrad J. Kossacki, Wojciech J. Markiewicz

\section{To cite this version:}

Konrad J. Kossacki, Wojciech J. Markiewicz. Small-scale trench in the North polar region of Mars: evolution of surface frost and ground ice concentration. Icarus, 2008, 199 (1), pp.75. 10.1016/j.icarus.2008.09.003 . hal-00499095

\section{HAL Id: hal-00499095 https://hal.science/hal-00499095}

Submitted on 9 Jul 2010

HAL is a multi-disciplinary open access archive for the deposit and dissemination of scientific research documents, whether they are published or not. The documents may come from teaching and research institutions in France or abroad, or from public or private research centers.
L'archive ouverte pluridisciplinaire HAL, est destinée au dépôt et à la diffusion de documents scientifiques de niveau recherche, publiés ou non, émanant des établissements d'enseignement et de recherche français ou étrangers, des laboratoires publics ou privés. 


\section{Accepted Manuscript}

Small-scale trench in the North polar region of Mars: evolution of surface frost and ground ice concentration

Konrad J. Kossacki, Wojciech J. Markiewicz

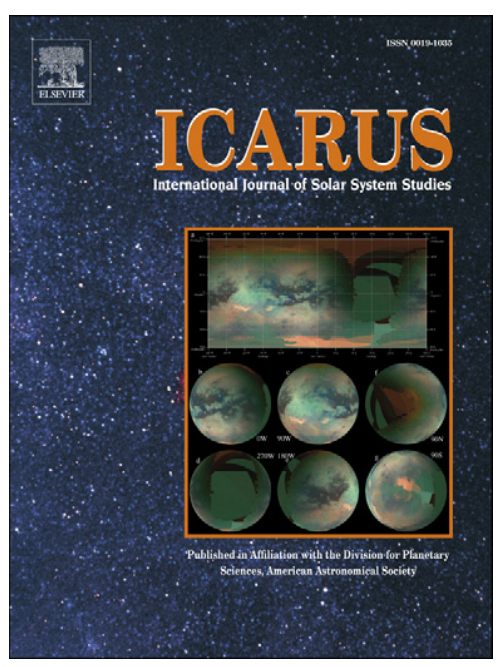

PII:

S0019-1035(08)00320-5

DOI: $\quad$ 10.1016/j.icarus.2008.09.003

Reference: $\quad$ YICAR 8760

To appear in: Icarus

Received date: 26 February 2008

Revised date: 3 September 2008

Accepted date: 9 September 2008

Please cite this article as: K.J. Kossacki, W.J. Markiewicz, Small-scale trench in the North polar region of Mars: evolution of surface frost and ground ice concentration, Icarus (2008), doi:

10.1016/j.icarus.2008.09.003

This is a PDF file of an unedited manuscript that has been accepted for publication. As a service to our customers we are providing this early version of the manuscript. The manuscript will undergo copyediting, typesetting, and review of the resulting proof before it is published in its final form. Please note that during the production process errors may be discovered which could affect the content, and all legal disclaimers that apply to the journal pertain. 


\title{
Small-scale trench in the North polar region of Mars: evolution of surface frost and ground ice concentration.
}

\author{
Konrad J. Kossacki \\ Institute of Geophysics of Warsaw University, Pasteura 7, 02-093 Warsaw, \\ Poland, \\ e-mail: kjkossac@fuw.edu.pl \\ Wojciech J. Markiewicz \\ Max Planck Institute for Solar System Research, Max-Planck-Str 2, D-37191 \\ Katlenburg-Lindau, Germany
}

Number of pages (including figures): 24

Number of figures: 9 
Please send Editorial Correspondence to:

Konrad J. Kossacki

Institute of Geophysics of Warsaw University

Pasteura 7

02-093 Warsaw, POLAND

Tel: (48) 225546834

Fax: (48) 225546882

E-mail: kjkossac@igf.fuw.edu.pl

Proposed Running Head:

Small-scale trench 


\begin{abstract}
In this paper we attempt to answer the question, how formation of a small-scale trench in the Martian regolith affects local distribution of the subsurface ice. We are especially interested in the consequences of digging a trench to search for buried ice, as has been done during the Phoenix Mars Lander mission. However, the results may be also applicable for natural troughs, or cracks. We present results of simulations of diurnal exchange of water between the regolith and the atmosphere. Our model includes the heat and vapor migration in the regolith surrounding the trench, as well as formation of diurnal frost. We take into account scattering of light in the atmosphere and on the trench facets, as well as changes of atmospheric humidity on diurnal and seasonal time scales. Our calculations show, that the measurements of ice content in a sample obtained within one, or two days from the beginning of digging should not be affected. However, on somewhat longer time scale at the south facing site of the trench the regolith can be significantly depleted from ice. This effect should be taken into account if the excavation and taking samples from different depths will be performed in stages separated in time by a month, or more.
\end{abstract}

Key words: Mars, Surface, Water 


\section{Introduction}

Our work is intended to simulate evolution of the surface frost in a small trench, like these dug by the Phoenix Mars Lander. We calculated also evolution of the ground ice beneath the trench. We performed our simulations before landing and the successful digging in Martian regolith. Thus, we consider properties of the regolith deduced by several authors using remote observations. Below, we present short review of the estimates regarding composition of the regolith.

The opinions about the amount of water present on Mars significantly evolved during past decades. Theoretical simulations performed by many authors (Leighton and Murray, 1966; Fanale et al., 1986; Mellon and Jakosky, 1995; Schorghofer and Aharonson, 2005; Aharonson and Schorghofer, 2006) led finally to the conclusion, that the subsurface ice may be present in wide range of latitudes. The neutron and gamma ray spectrometers on board Mars Odyssey spacecraft confirmed, that some subsurface ice is present almost everywhere on Mars except low latitudes (Boynton et al., 2002; Mitrofanov et al., 2004). This is in agreement with other observations (Kossacki et al., 2003; Titus et al., 2003). Direct search for the subsurface ice was planned for the failed Mars Polar Lander mission. Now, similar experiment involving excavation of a trench is performed by the Phoenix lander. The regions initially considered for the landing of Phoenix were at the latitude about $70^{\circ} \mathrm{N}$. The final landing site is at $68.16^{\circ} \mathrm{N}, 233.35^{\circ} \mathrm{E}$.

At the latitude as high as $70^{\circ}$ regolith was commonly expected to be rich in ice. However, high resolution observations of the surface temperature indicated that the subsurface concentration of ice on depths up to ten centimeters can be nonuniform and locally very low. This made various theoretical studies important for the preparation of the digging experiment. Sizemore and Mellon (2006) simulated possible non-uniformity of the ground-ice distribution in heterogeneous Martian subsurface. They found, that presence of buried decimeter scale rocks should create some depressions in the ice table over a horizontal range of 1 - 2 rock radii. They also found that, dust lenses of the same scale may locally reduce depth to the ground ice by few centimeters. Small-scale heterogeneity of the regolith, as described above, and the related non-uniformity of the ground ice distribution should affect thermal inertia. This problem was recently investigated by Putzig and Mellon (2007b). The authors calculated thermal inertia based on day time and nigh-ttime observations performed using the Mars Global Surveyor Thermal Emission Spectrometer (three Martian years). At low latitudes the derived apparent thermal inertia is only moderately dependent on local time, but in the polar regions diurnal differences locally exceed $600 \mathrm{~J} \mathrm{~m}^{-2} \mathrm{~K}^{-1} \mathrm{~s}^{-1 / 2}$. Based on the comparison between the results of modeling and the seasonal maps of the thermal inertia 
Putzig and Mellon (2007b) concluded that in the polar regions ground ice is typically covered by ice-free sand. Similar result was obtained by Bandfield (2007), who compared observations performed using the Thermal Emission Imaging System (THEMIS) on the Mars Odyssey spacecraft with results of thermal simulations.

Another problem is local inclination of the surface. Fergason et al. (2006) compared the night time temperatures of slopes at different orientations. For low and moderate inclinations up to $30^{\circ}$ the temperatures of the opposite facing slopes appeared to be the same to within few degrees. However, Fergason et al. (2006) did not analyze areas at high latitudes, where the zenith angle of the Sun is much larger. Thus, their result is not applicable for Phoenix mission. More recently Putzig and Mellon (2007a) compared apparent thermal inertia calculated for surfaces either horizontal, or partially sloped. The authors state, that their result are applicable to mixtures where the material properties vary at scales larger than a thermal skin depth. Analysis of high resolution HiRISE stereo images (down to $2 \mathrm{~m}$ length scale) indicates that in the area selected for the Phoenix landing site rocks abundances are low and slopes are typically $<3^{\circ}$ even at fine scales (Arvidson et al., 2007). Thus, in our work dealing with the trough up to meter scale we assume, that the surface is horizontal and initially flat.

Digging a trench disturbs temperature field in the regolith. It should also result in direct contact of the uncovered layers with the atmosphere. Both effects may lead to significant changes of ice content in the regolith surrounding the trench and hence of ice content of the sample analysed by the Phoenix instruments. In this work we attempt to answer two questions: (i) how fast are changes of the subsurface ice content in the regolith induced by digging, and (ii) how much frost can form in the trench due to condensation of the atmospheric vapor.

\section{Model}

We use the LWMRM (Lindau-Warsaw-Mars-Regolith-Model) model which was initially developed to simulate thermal conditions for the formation of frost in the trench to be excavated during Mars Polar Lander mission (Kossacki et al., 2001). In subsequent applications of LWMRM we improved its accuracy, allowed for more complex geometries and implemented more physical processes. The most recent versions were used to investigate the possibility of seasonal ice melting in the Martian gullies (Kossacki and Markiewicz, 2004), and to simulate the escape rate of subsurface ice in the southern part of the Elysium region (Kossacki et al., 2006). In the current version we modified the way of calculating the condensation of atmospheric vapor in the regolith. 
Below we briefly describe the main features of the LWMRM model. Farther details can be found in the references listed above.

The LWMRM model describes diurnal and seasonal condensation and sublimation cycle of $\mathrm{H}_{2} \mathrm{O}$ and $\mathrm{CO}_{2}$ ices within a Martian trench, or crater, and in the surrounding regolith. In the current work we are interested in a trench. The regolith is composed of equal size dust grains mantled by ice if this is present. The thickness of ice covering a dust grain is uniform and is determined by the local volume of ice in the regolith. In real situation ice can migrate along the surface of a grain due to local differences of curvature of the surface. However, including this effect significantly reduces speed of calculations. Thus, we consider only instantaneous thickness of ice mantling the grains. The model includes the time dependent solar illumination, infrared emission from the atmosphere toward surface, infrared emission from the surface, heat and vapor transport within the regolith and the heat exchange due to sublimation and condensation. The flux of absorbed light depends on the local orientation of the facets (wall or bottom) and on the current position of the Sun. The latter evolves due to orbital motion and rotation of Mars. The model includes absorption of direct solar light, as well as light scattered once within the considered trench. Infrared emission from the facets is considered as well, including their relative orientations. For the absorption of the infrared radiation from the atmosphere we take into account fraction of the sky visible in a given location in the trench. The total IR radiation emitted by the atmosphere toward surface can be either parametrized, or taken from results of a general circulation model such as GCM LMD/Oxford (Forget et al., 1999; Lewis et al., 1999), available at http://www-mars.lmd.jussieu.fr/. In the current work we use the latter option. The seasonal and diurnal variations of atmospheric pressure and humidity are also taken from the results of LMD/Oxford GCM. Our model allows including both seasonal and diurnal cycles of atmospheric IR emission. However, during polar night when the atmospheric IR radiation has highest relative influence the GCM results have low accuracy. Thus, we include only seasonal changes of the atmospheric IR emission. Formation of ice due to condensation of water vapor from the atmosphere was in the previous versions of our model restricted to the surface. Now, as long as the surface ice is thinner than the size of grains composing regolith, ice condenses simultaneously on the surface (including trench facets) and in the near surface layer of the regolith.

Our model, as all models describing water exchange between regolith and atmosphere, has several parameters. For present purpose most important is sensitivity of the model to the distribution of the subsurface ice. In the section 2.4 we show sensitivity of the calculated surface temperature and the frost thickness to the local content of the subsurface ice and to the atmospheric humidity. 


\subsection{Equations}

The main equations are those describing: local illumination, the rates of condensation and sublimation of ices on the surface, the diffusion of heat and vapor in the regolith, and the instantaneous local thickness of ice on the regolith grains.

The flux $F_{s}$ of the ice subliming from the facets of the trough, or from the external surface is determined by the pressure $p_{\text {sat }}$ at the local surface temperature. For the flux of condensing water vapor we use the modified equation proposed by Ivanov and Muhleman (2000). Here,

$$
F_{s, H_{2} \mathrm{O}}=u \beta\left(\frac{\mu_{\mathrm{H}_{2} \mathrm{O}}}{R T_{\mathrm{surf}}}\right)\left(P_{s, \mathrm{H}_{2} \mathrm{O}}-P_{\mathrm{H}_{2} \mathrm{O}}\right)
$$

where $u$ and $P_{H 2 O}$ are the horizontal wind speed and the partial pressure of vapor at the height $H$ above the surface. If it is not stated otherwise, $H$ $=1 \mathrm{~m} . P_{s, H 2 O}$ is the pressure of phase equilibrium between solid and gas $\mathrm{H}_{2} \mathrm{O}$ at the current temperature of ice surface $T_{\text {surf }}$. For the drag factor $\beta$ we applied the value 0.002 suggested by Paterson (1994) for Earth glaciers. The speed of wind can not be calculated without high resolution 3D simulation of the atmosphere, including topographic effects and the presence of the lander. Thus, we take $u$ as a parameter.

The diffusion of heat and vapor in the regolith, as well as the surface temperature strongly depend on the structure and the thermal conductivity of the regolith. Thermal conductivity itself depends on the regolith structure and the temperature. The regolith can be dry, or filled with some amount of ice. Thus, its thermal conductivity and the gas permeability can vary in wide ranges. In our work the regolith is a matrix of sand grains, with the void space partially filled by ice mantling mineral grains. The model accounts for sizes of the contact areas between the grains. These areas are determined by the local content of ice and the porosity. There are various formulas in the literature for the thermal conductivity of granular media. Here,

$$
\lambda=\lambda_{\mathrm{m}}+h\left(v_{\mathrm{i}}\right) \lambda_{\mathrm{i}} v_{\mathrm{i}}
$$

where $\lambda_{\mathrm{m}}$ is the conductivity of the ice-free matrix (dust), $\lambda_{\mathrm{i}}$ is the bulk thermal conductivity of ice, $v_{\mathrm{i}}$ is the volume fraction of ice, and $h$ is the Hertz factor. The latter is defined as the ratio between the grain-to-grain contact area and the effective cross-section of a grain including the ice coating of the grain if it exists. The functional form of $h\left(v_{\mathrm{i}}\right)$ depends on the microscopic model of the regolith. We assume that the ice mantle covering a mineral grain has 
uniform thickness, as it was described in the section 2. This allows calculation of the instantaneous value of $h$, determined by the time dependent $v_{i}$.

Complete set of equations included in the previous versions of the model is described in Kossacki and Markiewicz (2004), and Kossacki et al. (2006).

\subsection{Initial and boundary conditions}

In the current work we consider trench long when compared to its cross-section. The heat and vapor diffusion equations are solved in the plane perpendicular to the trench axis, hence in two dimensions. However, illumination of the trench is calculated in three dimensions, this makes the simulations 2.5 D. Boundary conditions on the facets of the trench and on the regolith surface external to the trench are variable. The temperature satisfies heat balance through the energy equation. The vapor flux is determined by the temperature, the atmospheric humidity and the wind speed. The latter is a free parameter. The numerical grid is large enough that the fluxes through the walls and the bottom of the grid are negligible. Thus, we assume zero values for the vertical heat and vapor fluxes at the bottom of the grid and zero horizontal fluxes at the sides of the grid.

Before simulating excavation we run the program for ten full Martian years. Thus, at the time of digging the temperature versus depth is not affected by the initial conditions. Therefore, we can assume uniform initial temperature of the regolith. The initial ice content $v_{i_{0}}$ increases linearly with depth from zero at the surface to $v_{i, \max }$ at some depth $d$. At larger depths $v_{i_{0}}=v_{i, \max }$.

\subsection{Parameters}

We consider trench excavated in an area similar to the landing site of Phoenix. We performed simulations when the exact latitude of the landing site was still unknown. We decided for the latitude $70^{\circ} \mathrm{N}$. The finally selected landing site is at the latitude $68.16^{\circ}$.

We look at simple, two stage scenario of excavating the trench. In the first stage we dig straight a way to the depth $D=20 \mathrm{~cm}$, and width at the bottom $L=40 \mathrm{~cm}$, with the side walls inclined by $45^{\circ}$ (like the trench dug in Beacon Valley Antarctica (Mellon et al., 2004)). In the second stage of digging, 3 sols later, we dig more to reach the depth of $30 \mathrm{~cm}$. The final trough is $20 \mathrm{~cm}$ wide at the bottom. The simulated trough is oriented either N-S, or E-W. The former orientation is approximately the same as planned for the trench to be excavated, while the latter is added to investigate conditions at the ends of 
the N-S trench. It should be noted, that there is some uncertainty of landing orientation, and the robotic arm has ability to pivot around the vertical axis. Thus, the exact orientation of the trench is a priori not known. The ends of the real trench will have complex shape, but will face approximately toward North and South, respectively. The simulated excavation starts at $\mathrm{L}_{s}=77.4^{\circ}$. The simulations are performed with spatial resolution of $5 \mathrm{~cm}$. The time step is 5 minutes.

In the regions considered as possible landing sites the regolith is two layered. The upper layer is $3-6 \mathrm{~cm}$ thick and has the thermal inertia slightly above $200 \mathrm{~J} \mathrm{~m}^{-2} \mathrm{~K}^{-1} \mathrm{~s}^{-1 / 2}$, while the lower layer has $20-50 \%$ of ice, and has thermal inertia $400-1100 \mathrm{~J} \mathrm{~m}^{-2} \mathrm{~K}^{-1} \mathrm{~s}^{-1 / 2}$ (Titus and Prettyman, 2007). Locally, around rocks thickness of the upper dry layer of the regolith may be significantly larger than $10 \mathrm{~cm}$ (Sizemore and Mellon, 2006). In our model the regolith is composed of single size spherical grains whose radii $r_{g}$ are $5 \mu \mathrm{m}$, or $0.5 \mathrm{~mm}$. The regolith density $\varrho$ is $1300 \mathrm{~kg} \mathrm{~m}^{-3}$, and the specific heat $c=$ $820 \mathrm{~J} \mathrm{~kg}^{-1} \mathrm{~K}^{-1}$. The porosity of the regolith, when it is free of ice, is 0.47 . The initial volume fraction of ice $v_{i_{0}}$ increases with depth from zero at the surface to $v_{i, \max }$ at the depth $d$. At any depth below $d$, ice volume $v_{i_{0}}=v_{i, \max }$. In our canonical case $v_{i, \max }=0.38$. This value corresponds to porosity of about 0.1 , while the percolation threshold is typically $0.2-0.3$. Thus, at $v_{i}=0.38$ most pores are closed and we can consider the regolith as effectively saturated with ice. We consider two values of $d: 0.2 \mathrm{~m}$ and $0.5 \mathrm{~m}$. If it is not stated otherwise $d=0.5 \mathrm{~m}$. Thermal conductivity $k\left(v_{i}\right)$ of the regolith is calculated accounting for the contact areas of the grains, which in turn is related to the porosity. Condensation and sublimation of ice within this matrix modifies the conductivity according to how much ice is present at any particular time and place. The thermal conductivity of the regolith free of ice $k\left(v_{i}=0\right)$ is 0.01 $W m^{-1} K^{-1}$. Thus, in our model thermal inertia linearly increases versus depth from $100 \mathrm{~W} \mathrm{~m}^{-1} \mathrm{~K}^{-1}$ at the surface to about $1000 \mathrm{~W} \mathrm{~m}^{-1} \mathrm{~K}^{-1}$ at the depth $d$. In addition, we performed simulations for the regolith of low ice content $\left(v_{i, \max }=0.09\right)$.

The albedo of ice covered surface strongly depends on the purity of ice, and the ice granulation. In our model albedo has one of two values: $A$ for the unfrosted surface, or the surface covered by ice thinner than $0.1 \mathrm{~mm}$, and $A_{i}$ for the surface covered by thicker ice. We consider $A=0.25$ and $A_{i}=0.35$.

The seasonal and diurnal variations of the atmospheric pressure and humidity are taken from the results of LMD/Oxford GCM. In both cases we have 4 data points per Martian day. Thus, we perform interpolation to get values of atmospheric pressure and humidity for each step of integration. The atmospheric pressure in the considered region is about $1000 \mathrm{~Pa}$. According to Tamppari et al. (2007) it should be within the range 700 - 1100 Pa. GCM LMD/Oxford used in our work predicts similar range 730 - $940 \mathrm{~Pa}$. According to this model 
the atmospheric humidity expressed by the water vapor mixing ratio is ranging from $310^{-9}$ to $210^{-3}$. In Fig. 1 we show water vapor mixing ratio versus time at the altitude $5 \mathrm{~m}$ above the local surface. The corresponding condensation temperature is plotted as well. The profile of the mixing ratio is drawn for the whole Martian year. Thus, for the diurnal oscillations only highest and lowest values can be distinguished. The plotted profile of the condensation temperature shows, that at the time of digging the trench water frost should condense in locations colder than 195 - 215 K. Diurnal minimum of the condensation temperature is predicted for morning hours. During the day time, when the surface temperature rises, the condensation temperature rises as well.

The IR radiation emitted by the atmosphere toward surface is also taken from the results of GCM. In this case we use GCM data averaged over diurnal and seasonal time scales to get 16 points per Martian year. The wind speed $u$ at elevation 5 meters above the surface is either $5 \mathrm{~m} \mathrm{~s}^{-1}$, or $20 \mathrm{~m} \mathrm{~s}^{-1}$. The latter is the highest wind speed considered as acceptable for the Phoenix landing site (Arvidson et al., 2007).

\subsection{Sensitivity of the model}

In this subsection we present briefly sensitivity of our model to most important parameters. The current paper is intended to present results of simulations for the particular location on Mars, where they can be compared with the in-situ observations. Thus, it is not necessary to discuss influence of latitude and elevation. They are determined by the location of the Phoenix landing site. The most important is sensitivity of the results to the volume fraction of ice beneath the trench.

In Fig 2 we demonstrate sensitivity of the model to the local content of the subsurface ice, and to the atmospheric humidity. Plotted are; the temperature versus time, and the frost thickness versus time. The profiles are drawn for the middle of the bottom of the $30 \mathrm{~cm}$ deep trench, starting from the second stage of digging (increase of the depth from $20 \mathrm{~cm}$ to $30 \mathrm{~cm}$ ). The volume fraction of ice $v_{i}$ just beneath the trench bottom is either 0.04 , or 0.17 . The atmospheric humidity is taken from the results of GCM LMD/Oxford (thin black lines), or modified (thick grey lines). The grey curves correspond to the situation when the volume fraction of ice beneath the trench is 0.17 and the humidity is: $2 \mathrm{x}$ higher, and $2 \mathrm{x}$ lower than predicted by the GCM.

The calculated profiles of the temperature are significantly different. Amplitude of the diurnal oscillations is: $60 \mathrm{~K}$ and $30 \mathrm{~K}$ respectively. The highest diurnal temperatures are, $200 \mathrm{~K}$ and $220 \mathrm{~K}$. The condensation temperature oscillates in diurnal cycle from $200 \mathrm{~K}$ to $215 \mathrm{~K}$. Close to noon, when the 
bottom of the trench is warmest, condensation temperature is about $210 \mathrm{~K}$. Hence, periodical disappearing of the surface frost may be determined by the concentration of the subsurface ice beneath the trench. Comparison of the frost thickness calculated using different profiles of the atmospheric humidity versus time shows high importance of the local near-surface humidity. The average condensation rate of the surface frost changes proportionally to the average humidity. When the ground ice content beneath the trench is high and the humidity is reduced, the frost thickness increases with the average rate as predicted for low subsurface ice content and the GCM humidity.

\section{Results}

In Fig. 3 we show diurnal cycle of the surface temperature within the N-S oriented trench, after the first phase of digging (the trench is $20 \mathrm{~cm}$ deep). In addition we show temperature profile for the surface external to the trench, $20 \mathrm{~cm}$ away of the trench edge. Wind speed is taken to be $5 \mathrm{~m} / \mathrm{sec}$. Ice volume in the regolith is high $\left(v_{i}=0.38\right.$, upper panel $)$, and low $\left(v_{i}=0.09\right.$, lower panel). Wall 1 is the east facing west wall and wall 2 is the west facing wall. According to our simulations, just after excavation ice volume $v_{i}$ beneath the bottom of the trench is: 0.11 and 0.03 , respectively. When the ice content is high, the temperature in the trench never falls below $165 \mathrm{~K}$, even in the most shadowed locations. The situation changes when the regolith beneath the trench is almost free of ice and has low thermal inertia. In this case the lowest temperatures are slightly above $150 \mathrm{~K}$. During the first evening after digging the trench, temperature of the east facing wall allows even formation of the $\mathrm{CO}_{2}$ frost.

In Fig. 4 we show profiles of the surface temperature and of the frost thickness in the E-W oriented trench. The north facing wall is coldest, as it should be expected. It is illuminated only at night, when the zenith angle of the Sun is large. The angle between the direction to the Sun and the direction normal to the wall is also large. At midnight it is $40^{\circ}$, but in the morning and in the evening it exceeds $60^{\circ}$. This may indicate, that the north facing wall should be warmest at midnight. However, when the Sun is very close to the horizon light is strongly attenuated. Thus, in the evening and in the morning the north facing wall is about $10 \mathrm{~K}$ warmer than at midnight. Nevertheless, it is always cold. In the selected point $10 \mathrm{~cm}$ beneath the upper edge, amplitude of the diurnal oscillations is $25 \mathrm{~K}$ and the minimum of the temperature is about $165 \mathrm{~K}$. For the south facing wall minimum of the temperature is about $75 \mathrm{~K}$. The temperatures indicate, that the north facing wall should start collecting frost immediately after digging the trench. This conclusion is confirmed by the profiles of the frost thickness discussed further. 
In Fig. 5 we show the temperature cycles in three places on the bottom of the trench after the second stage of digging to $30 \mathrm{~cm}$ depth. Ice volume in the regolith is high $\left(v_{i}=0.38\right)$. The profiles are for the middle of the bottom of the trough and for two locations $5 \mathrm{~cm}$ away of the middle. All three curves almost overlap. The highest temperatures are about $200 \mathrm{~K}$. This value is 10 degrees lower than predicted for the shallower trench. At night time the temperature falls down to about $170 \mathrm{~K}$. The differences between temperatures in the trenches of different depths are due to different illumination, as well as due to different ice content beneath the trenches. The latter affects the thermal inertia and hence amplitude of the temperature oscillations.

In Fig. 6 we present profiles of the frost thickness versus time, after the second phase of digging. The trench is oriented N-S, or E-W. The regolith has high ice content $\left(v_{i, \max }=0.38\right)$, or low ice content $\left(v_{i, \max }=0.09\right)$. The profiles are for two points on the walls, $10 \mathrm{~cm}$ beneath the upper edges, and in the middle of the bottom of the trench. When the trench is oriented N-S, in the selected locations on the walls frost disappears when the temperature locally reaches diurnal maximum. However, at the bottom of the trench frost accumulates from day to day. Both results are in agreement with the profile of the condensation temperature shown in Fig. 1. This profile shows, that at the time of digging the trench water frost should appear in locations colder than $195-210 \mathrm{~K}$. Hence, in the middle of the bottom of the trench the temperature is the whole time below the frost point. Content of ice beneath the trench has moderate influence. In the considered cases $v_{i}$ beneath the trench is: 0.17 when $v_{i, \max }=0.38$, but only 0.04 when $v_{i, \max }=0.09$. In the former case frost cover on the bottom of the trench increases in thickness approximately 2 times faster than in the latter one. This is because higher volume of ground ice results in higher thermal inertia and hence in lower day time temperatures. When the trough is oriented E-W, profiles of the frost thickness for the bottom and the north facing wall of the trough almost overlap. It should be noted, that the thickness of the frost is in all cases very small reaching a value of 11 micron after 10 sols. Increasing wind speed to $20 \mathrm{~m} / \mathrm{sec}$ results in the maximum frost thickness reaching about 45 microns, still a small value. This should not affect measurement of the ice content in the regolith samples taken from the trench short time after digging.

Fig. 7 is analogous to the upper panel of Fig. 6. Different is the depth $d$, now it is only $0.2 \mathrm{~m}$ instead of $0.5 \mathrm{~m}$. It can be seen, that after 8 sols frost starts accumulate on the walls, where previously it was present only periodically. However, accumulation is slow and may cease due to some decrease of the atmospheric humidity.

Fig. 8 presents changes of the ice content in the regolith at and beneath facets in both N-S and E-W oriented trenches. The profiles are drawn for selected points at: the east wall (N-S trench), the north and south walls (E-W trench), 
and on the bottom (E-W trench). For each of the considered walls the curves are for a point $10 \mathrm{~cm}$ beneath the upper edge (point A) and a point $7 \mathrm{~cm}$ beneath the wall, in the direction perpendicular to the wall (point B). For the bottom of the trough we show content of ice in a point in the middle of the trench width. For this point are drawn two profiles: for the regolith rich in ice, and for the regolith of low ice content. The wind speed has largest of the considered values, $20 \mathrm{~ms}^{-1}$. This makes the calculated desiccation rate of the regolith an upper estimate. Decreasing the wind speed proportionally decreases the desiccation rates. The plotted volume fractions of ice are normalized to the local values of ice volume $v_{i, r e f}$ at $L_{s}=75^{\circ}$, few sols before digging the trench. Drawn are profiles of $v_{i} / v_{i, r e f}$. In the selected locations at the walls (points A) ice concentration in the regolith increases, or decreases depending of conditions. In both cases changes of $v_{i} / v_{i, r e f}$ are significant. At the south facing wall of the E-W oriented trench (within the first numerical cell) ice can disappear from the regolith within about 20 sols. At the bottom of the trough ice content in the regolith increases in all studied cases. The ice volume changes by about $20 \%$ just beneath the bottom, but already 5 centimeters beneath the trough changes are small.

In Fig. 9 we show changes of the ice content at different depths in the regolith beneath the south facing wall. The profiles are drawn versus distance perpendicular to the wall from the point $\mathrm{A}$ at the wall. The curves are for $L_{s}=77.4^{\circ}$ (just after digging the trough) and for $L_{s}=81^{\circ}$. It can be seen, that the dessication of the regolith is visible within a few centimeters beneath the wall already after this short time.

\section{Conclusions}

In this work we investigated influence of digging the decimeter scale trench, as now performed by Phoenix lander, on two processes: (i) formation of the surface frost within the trench, and (ii) changes of the ice content in the regolith surrounding the trench. Fast formation of frost in the shadowed locations, as well as quick changes of the subsurface ice distribution may have significant effect on the planned measurements. Small- and medium scale troughs on Mars were described in several papers dealing with polygonal features (e.g.Mellon (1997); Kuzmin et al. (2003); Kossacki et al. (2003); Mangold (2005); Page (2007); Haltigin et al. (2008); Mellon et al. (2008)). However, authors focused attention on the troughs large enough to be identifiable in satellite images. Most commonly investigated topics seem: formation of the troughs (Mellon, 1997), correlation of the polygonal troughs with other features indicating presence of the subsurface ice (Kuzmin et al., 2003; Kossacki et al., 2003), and determining past climate on Mars (Mangold, 2005). To our knowledge short time changes of ice content in and around small (decimeter scale) troughs is 
for the first time simulated in details in the present work.

Our simulations show, that the surface frost should accumulate on the bottom of the considered trough independently of the conditions (depth of the trough, wind speed and the ice content beneath the trench. When the trough is oriented $\mathrm{E}-\mathrm{W}$, or when the depleted in ice upper layer of the regolith is thin, frost should accumulate also locally on the walls of the trough. However, the amount of frost is not large. When the wind speed is $5 \mathrm{~m} \mathrm{~s}^{-1}$ frost thickness should not increase faster than about 1 micron per sol. Increasing the wind speed to $20 \mathrm{~m} \mathrm{~s}^{-1}$ may result in the formation of about $0.1 \mathrm{~mm}$ of frost during 20 sols. This should be already taken into account. South facing wall can be significantly depleted of water within a few sols. Thus, taking into account low amount of frost accumulated during first sols, the best locations to take samples of the regolith short time after digging the trench is its bottom.

If the regolith surrounding the trench is almost free of ice, surface frost should be taken into account.

\section{Acknowledgments}

This work was partially supported by the Polish Ministry of Education and Science (grant 0576/H03/2007/32). 


\section{References}

Aharonson, O, and Schorghofer, N., 2006. Subsurface ice on Mars with rough topography. J. Geophys. Res111, E1107, doi:10.1029/2005JE002636

Arvidson, R.E., Adams, D., Bandfield, J., Barge, L., Barnes, J., Boynton, W., Christensen, P., and 28 colleagues, 2007. Overview of Mars Exploration Program 2007 Phoenix Mission Landing Site Selection. Lunar and Planetary Science XXXVIII, 3204.

Bandfield, J.L., 2007. High-resolution subsurface water-ice distributions on Mars. Nature 447, 64-67

Boynton, W. V., 2002. Distribution of hydrogen in the near surface of Mars: Evidence for subsurface ice deposits. Science 297, 81-85.

Fanale, F. P., Salvail, J.R., Zent, A. P., and Postawko, S. E., 1986. Global distribution and migration of subsurface ice on Mars. Icarus 67, 1-18.

Fergason, R.L., Christensen, P.R., and Kieffer, H.H., 2006. High-resolution thermal inertia derived from the Thermal Emission Imaging System (THEMIS): Thermal model and applications J. Geophys. Res111, E12004, $1-22$.

Forget, F., F. Hourdin, R. Fournier, C. Hourdin, O. Talagrand, M. Collins, S. R. Lewis, P. L. Read, and J. Huot 1999. Improved general circulation models of the Martian atmosphere from the surface to above $80 \mathrm{~km}$. J. Geophys. Res, 104, 24,155-24,176.

Haltigin, T. W., Pollard, W. H., Osinski, G. R., Dutilleul, P., 2008. Comparative Morphometric Analysis of Polygonal Terrain at Potential Mars Phoenix Landing Sites. 2008LPI....39.2475H

Ivanov, A. B., and D. O. Muhleman, 2000. The Role of Sublimation for the Formation of the Northern Ice Cap: Results from the Mars Orbiter Laser Altimeter. Icarus, 144, 436-448.

Kossacki, K.J., Markiewicz, W.J., and Keller, H.U., 2001. Effect of Surface Roughness on Ice Distribution in the South Subpolar Region of Mars. Planet. Space Sc., 49, 437-445

Kossacki, K. J., Markiewicz, W.J., and Smith, M.D., 2003. Surface temperature of Martian regolith with polygonal features: influence of the subsurface water ice. Planet. Space Sci. 51, 569-580

Kossacki K. J., and Markiewicz, W.J., 2004. Seasonal melting of surface water ice condensing in Martian gullies. Icarus, 71, 272-283

Kossacki K. J., Markiewicz W. J., Smith M. D., Page D., Murray J, 2006. Possible remnants of a frozen mud lake in southern Elysium, Mars. Icarus, $181,363-374$

Kuzmin, R. O., Mitrofanov, I. G., Litvak, M. L., Boynton, W. V., Saunders, R. S. 2003. Mars: Detaching of the Free Water Signature (FWS) Presence Regions on the Base of HEND/ODYSSEY Data and Their Correlation with Some Permafrost features from MOC Data. 2003LPI....34.1369K

Leighton, R. R., and Murray, B. C., 1966. Behavior of carbon dioxide and other volatiles on Mars. Science 153, 136-144. 
Lewis, S. R., M. Collins, P. L. Read, F. . Forget, F. . . Hourdin, R. Fournier, C. Hourdin, O. Talagrand, and J. Huot, A climate database for Mars 1999. J. Geophys. Res, 104, 24,177-24,194

Mangold, N., 2005. High latitude patterned grounds on Mars: Classification, distribution and climatic control. Icarus, 174, 336-359

Mellon, M. T., and. Jakosky, B. M., 1995. The distribution and behavior of Martian ground ice during past and present epochs. J. Geophys. Res100, 11781-11799.

Mellon, M. T. 1997. Small-scale polygonal features on Mars: Seasonal thermal contraction cracks in permafrost. J. Geophys. Res, 102, 25,617-25,628.

Mellon, M. T., Feldman, W.C., and Prettyman, T.H., 2004. The presence and stability of ground ice in the southern hemisphere of Mars. Icarus 169, 324-340.

Polygonal Patterned Ground and Sorted Rocks on Mars as Seen by HiRISE: The Phoenix Landing Site, Northern Plains and Beyond. 2008 Mellon, M. T.; Arvidson, R. E.; Marlow, J. J.; Phillips, R. J.; Asphaug, E.; Searls, M. L.; Martinez-Alonso, S.; Hirise Team 2008LPI....39.1770M

Mitrofanov, I.G., et al., 2004. Soil water content on Mars as estimated from neutron measurements by the HEND instrument on-board the 2001 Mars Odyssey Spacecraft. Solar Syst. Res. 38, 253-257

Page, D.P., 2007. Recent low-latitude freeze thaw on Mars. Icarus, 189, 83-117.

Paterson, W. S. B., in The Physics of Glaciers, Elsevier, New York, 1994

Putzig, N.E., Mellon, M.T., 2007a. Thermal behavior of horizontally mixed surfaces on Mars. Icarus, 191, 52-67.

Putzig, N.E., Mellon, M.T., 2007b. Apparent thermal inertia and the surface heterogeneity of Mars. Icarus, 191, 68-94.

Schorghofer, N., and Aharonson, O., 2005. Stability and exchange of surface ice on Mars. J. Geophys. Res110, E5003, doi:10.1029/2004JE002350

Tamppari, L.K., Cantor, B.A., Friedson, A.J., Ghosh, A., Grover, M.R., Hale, A.S., Kass, D., Martin, T.Z., Mellon, M., Michaels, T., and 7 colleagues, 2007. Atmospheric Characteristics Expected at the Phoenix Landing Season and Location. Seventh International Conference on Mars, 3147.

Taylor, P. A., Baibakov, K., Brown, S., Hecht, M. H., Hudson, T. L., Li, P.Y., Lange, C. F., Prieto, L., Savelyev, S., 2006. On the sublimation of ice particles on the surface of Mars; with applications to the 2007/8 Phoenix Scout mission. Icarus, 181, 375-387

Titus, T.N., Kieffer, H.H., and Christensen, P.R., 2003. Exposed water ice discovered near the south pole of Mars. Science 299, 1048-1051.

Titus, T. N., Prettyman, T. H., 2007. Thermal Inertia Characterization of the Proposed Phoenix Landing Sites. Lunar and Planetary Science XXXVIII, 2088

Sizemore, H.G., and Mellon, T., 2006. Effects of soil heterogeneity on Martian ground-ice stability and orbital estimates of ice table depth. Icarus 185, 358-369. 

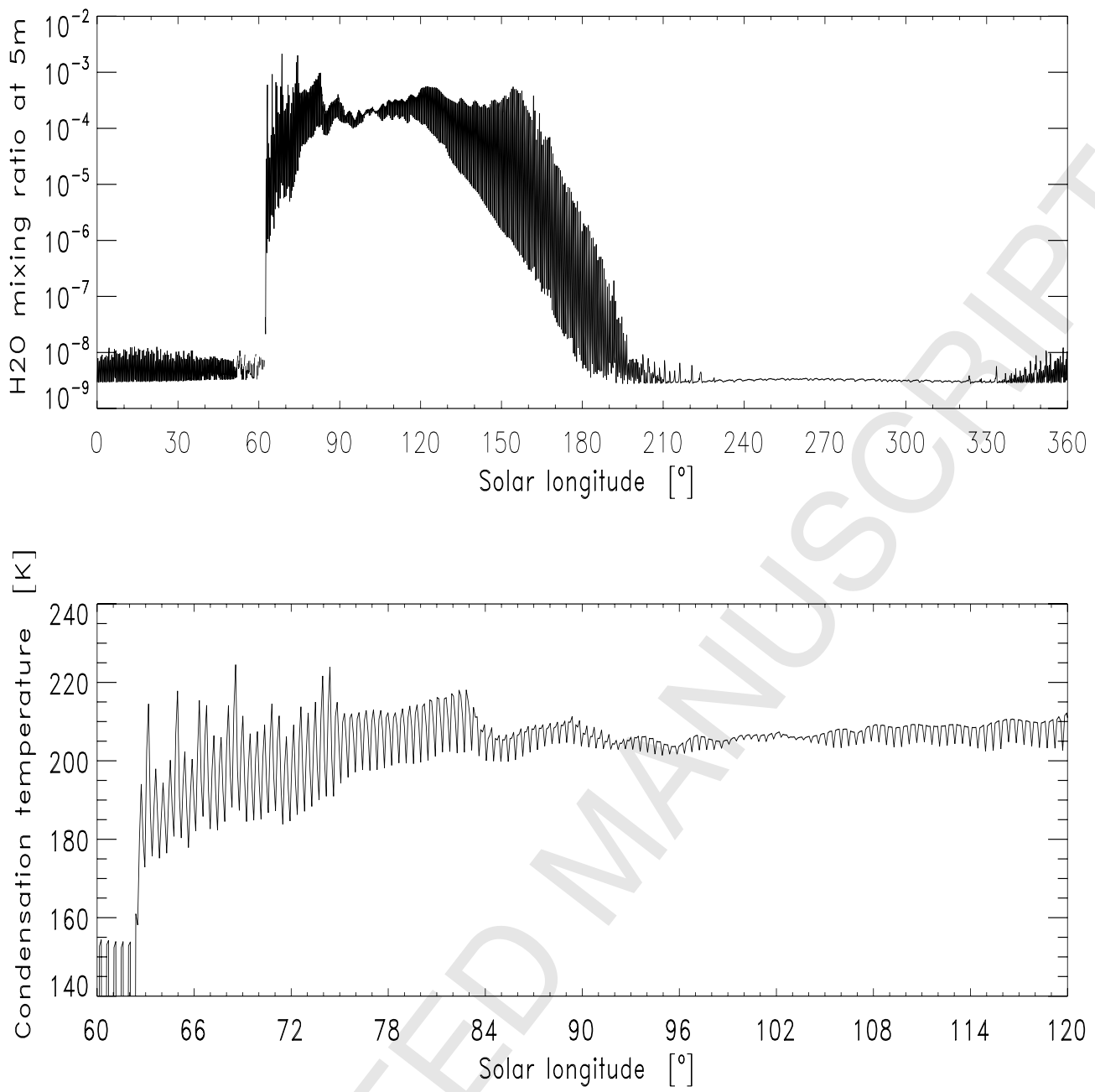

Fig. 1. Water vapor mixing ratio versus time at the altitude $5 \mathrm{~m}$ (upper panel), and the corresponding condensation temperature (lower panel). 

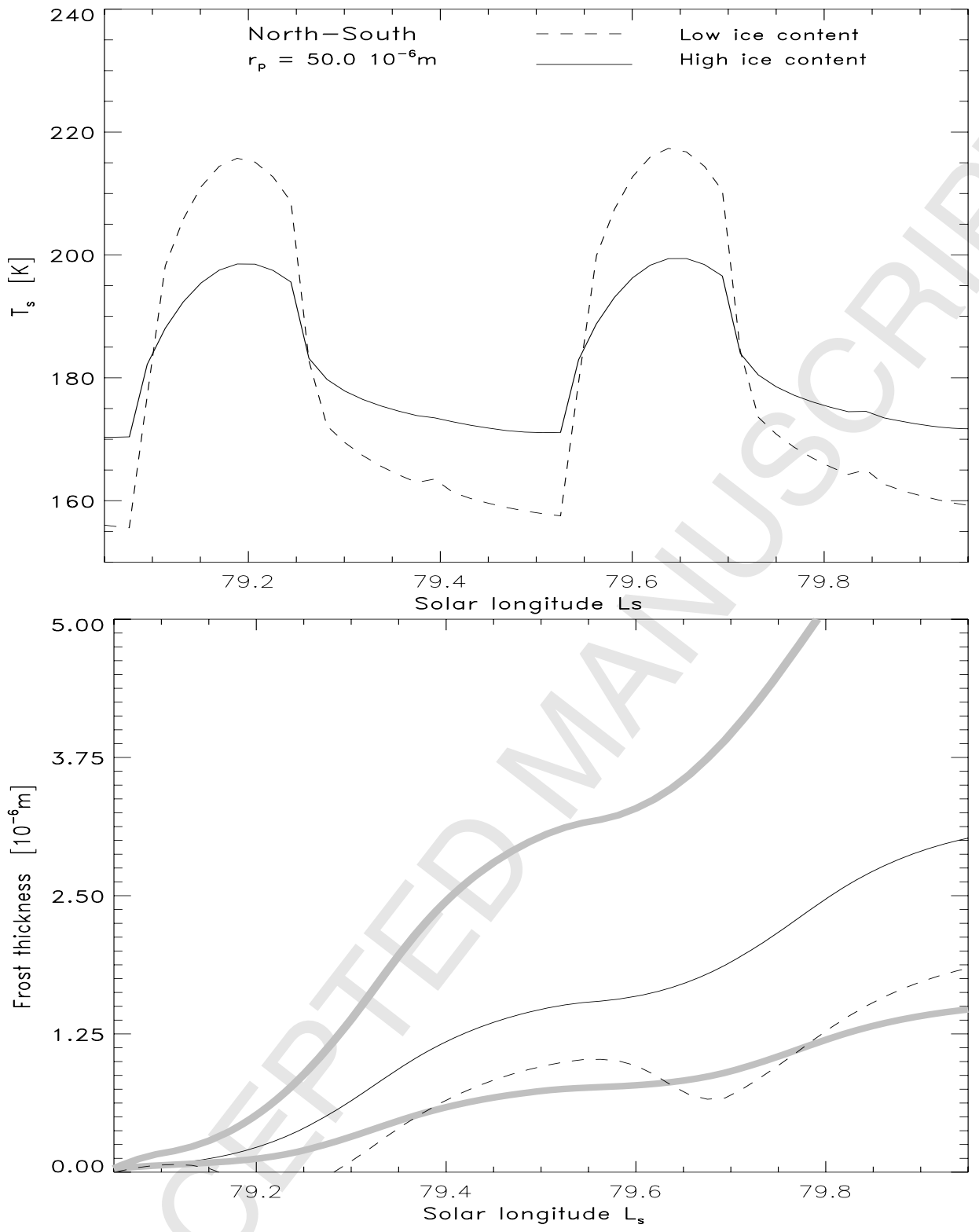

Fig. 2. Sensitivity of the model: to the local content of the subsurface ice, and to the atmospheric humidity. Plotted are: the surface temperature at the bottom of the trench (upper panel), and the frost thickness in the same location (lower panel). The depth of the trench is $30 \mathrm{~cm}$. The volume fraction of ice just beneath the trench bottom is either 0.04 (dashed line), or 0.17 (solid line). The atmospheric humidity is taken from the results of GCM LMD/Oxford (thin black lines), or modified (thick grey lines). The grey curves correspond to the situation when the volume fractions of ice beneath the trench is 0.17 and the humidity is: $2 \mathrm{x}$ higher (upper grey line), and $2 \mathrm{x}$ lower than predicted by the GCM (lower grey line). 

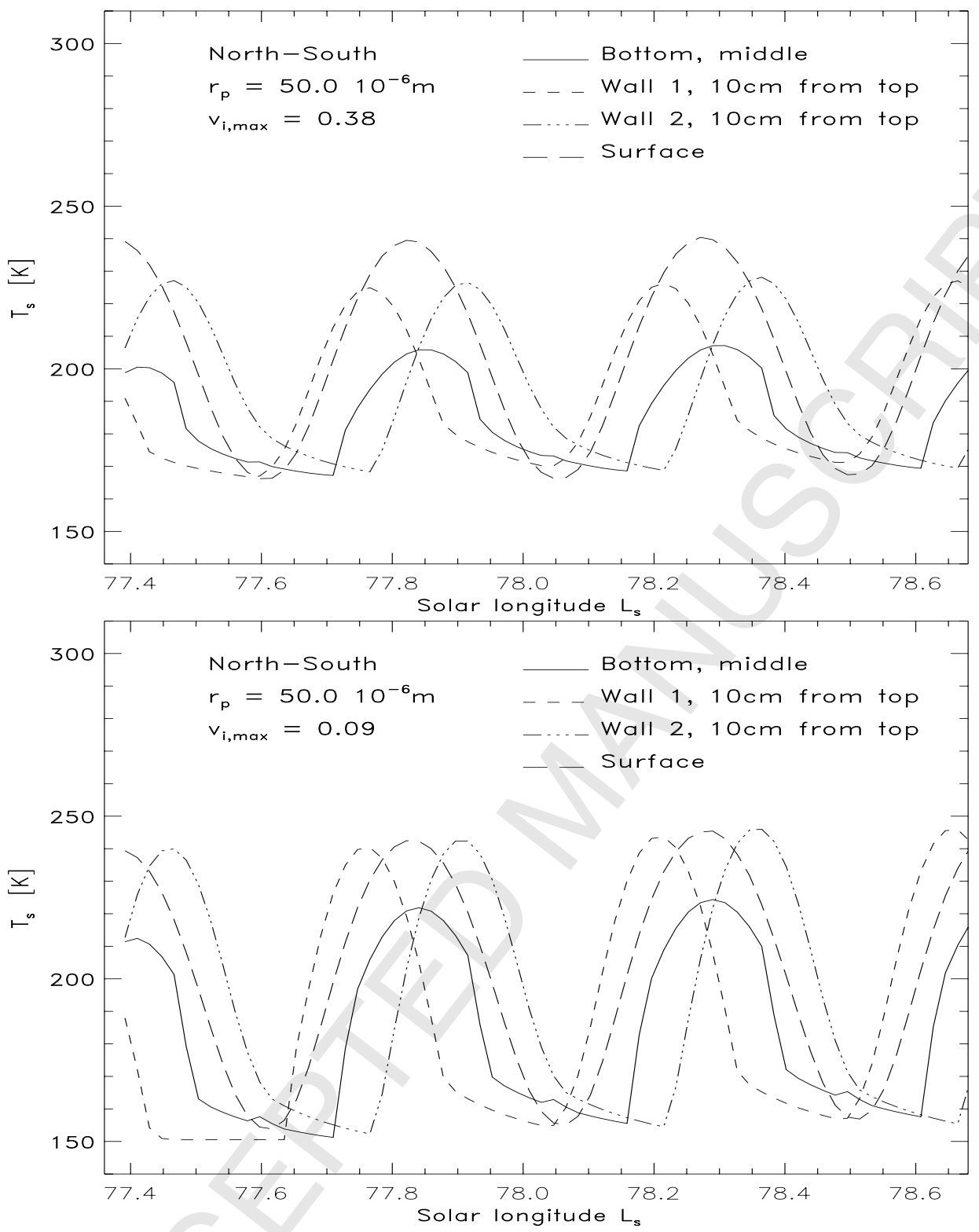

Fig. 3. Temperature within the N-S oriented trench. The depth is $20 \mathrm{~cm}$. The ice content in the regolith is either high (upper panel), or low (lower panel). In the former case $v_{i, \max }=0.38$, while in the latter $v_{i, \max }=0.09$. The profiles are for two points on the walls, $10 \mathrm{~cm}$ beneath the upper edge (points A), and in the middle of the trench bottom. Wall 1 is the east facing west wall and wall 2 is the west facing wall. In addition, profile for the surface external to the trench, $20 \mathrm{~cm}$ away of the trench edge is also shown. 


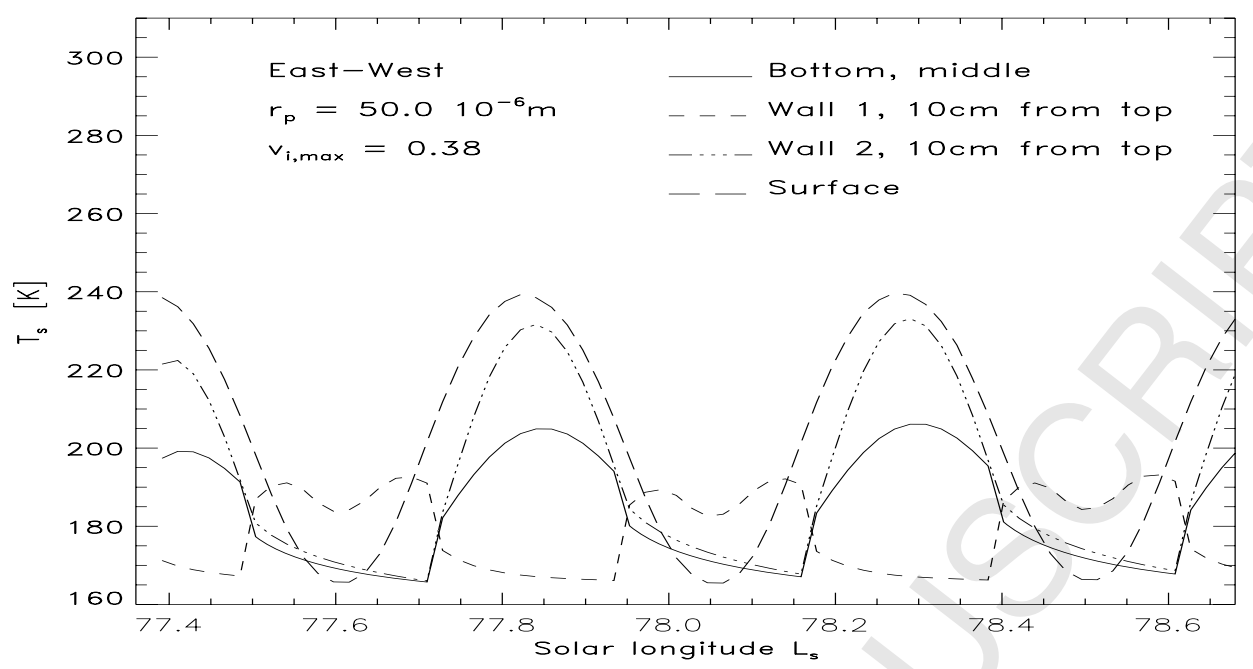

Fig. 4. As Fig, 3 but for trench oriented E-W. Wall 1 is the north facing south wall and wall 2 is the north wall. The profiles are drawn for the selected locations: on the walls, $10 \mathrm{~cm}$ beneath the upper edge; and the middle of the trench bottom.

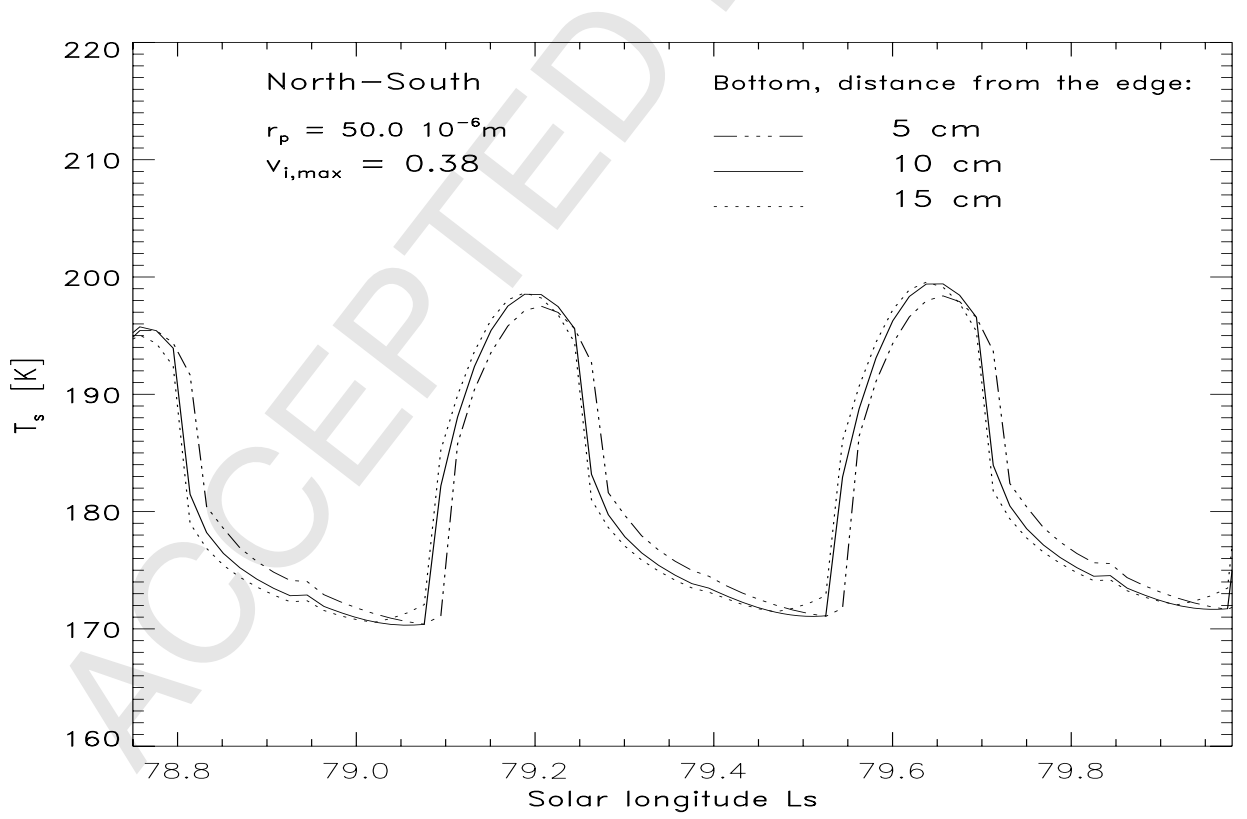

Fig. 5. As Fig. 3 but after the second stage of digging to $30 \mathrm{~cm}$ depth and for three locations on the trench bottom. 

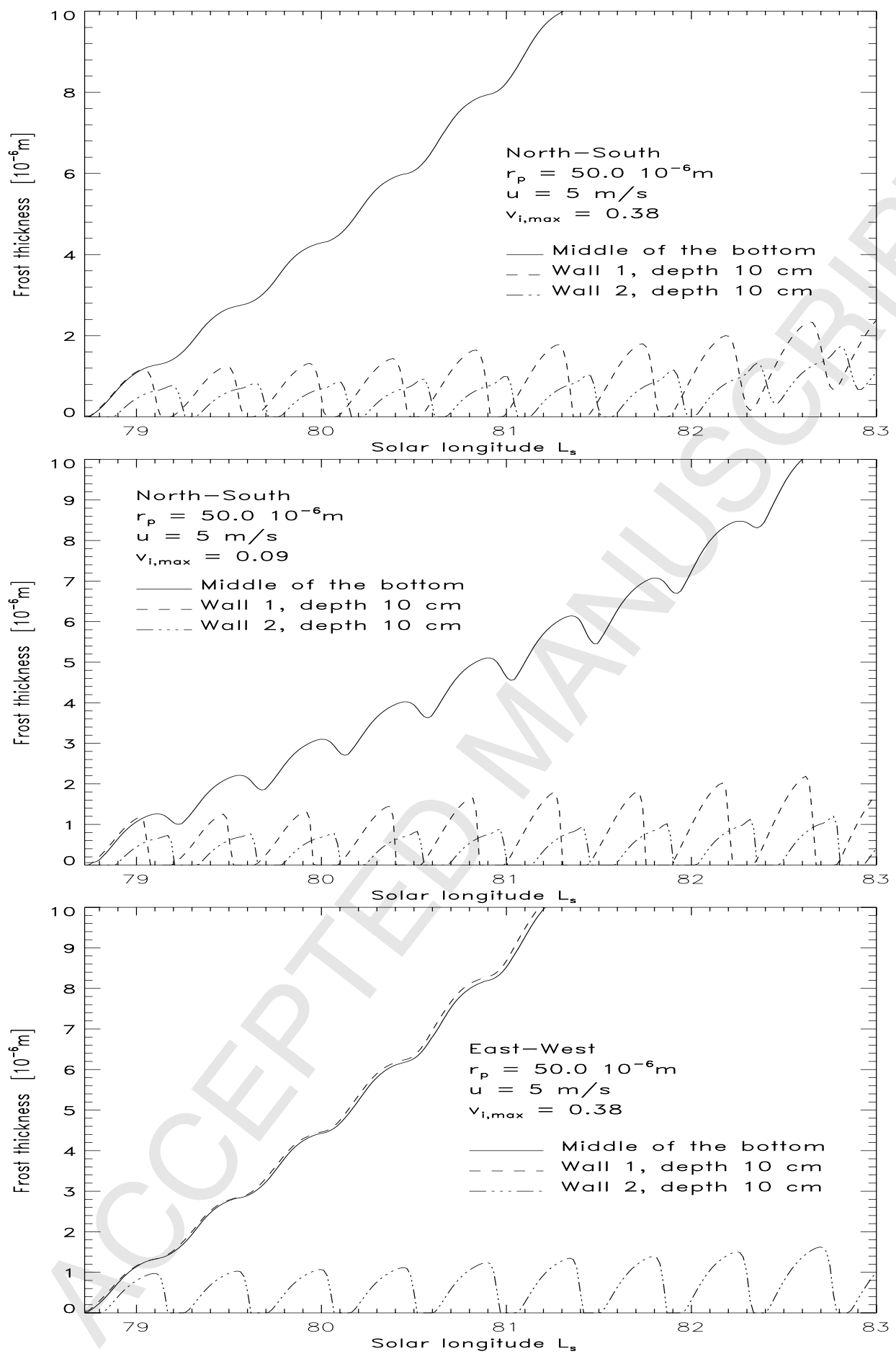

Fig. 6. Frost thickness as a function of time in trenches with both orientations, when the ice content in the regolith is high and low. The profiles are for two points on the walls, $10 \mathrm{~cm}$ beneath the upper edge, and in the middle of the trench bottom. Walls are defined as in the figures above. Wind speed is $5 \mathrm{~m} / \mathrm{sec}$. The value of $v_{i, \max }$ is 0.38 (upper and lower panels) and 0.09 (middle panel). 


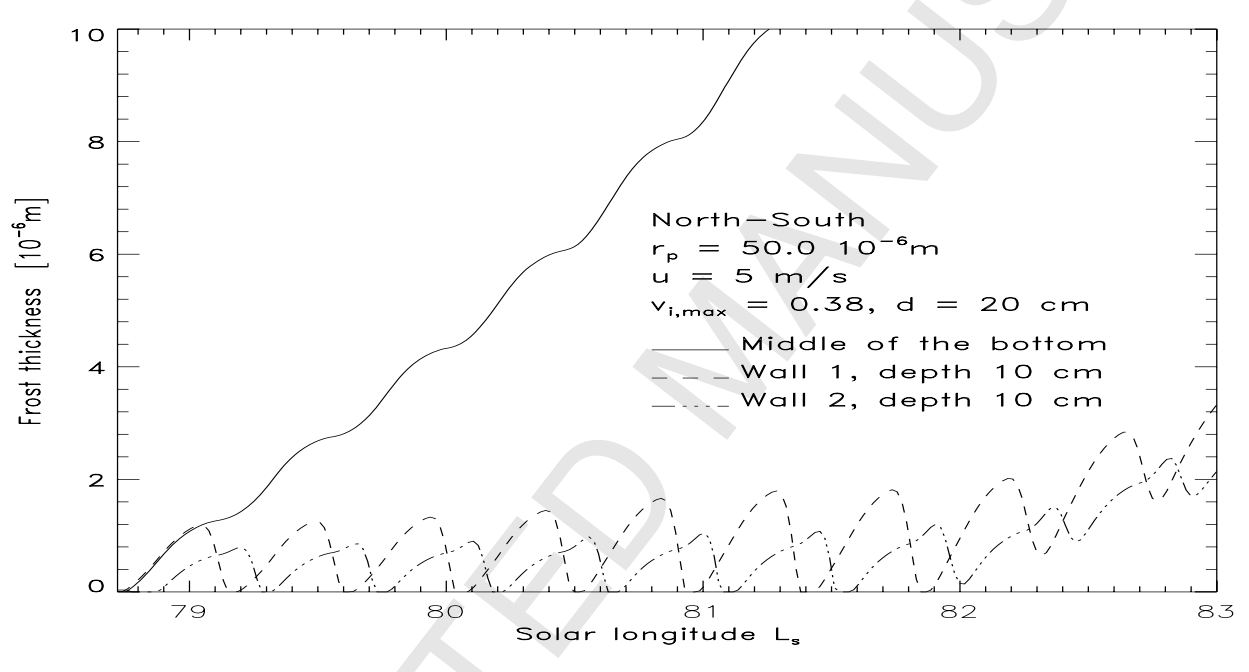

Fig. 7. As the upper panel of Fig. 6, but for small depth $d$ to the lower (filled with ice) layer of the regolith: $0.2 \mathrm{~m}$ instead of $0.5 \mathrm{~m}$. 

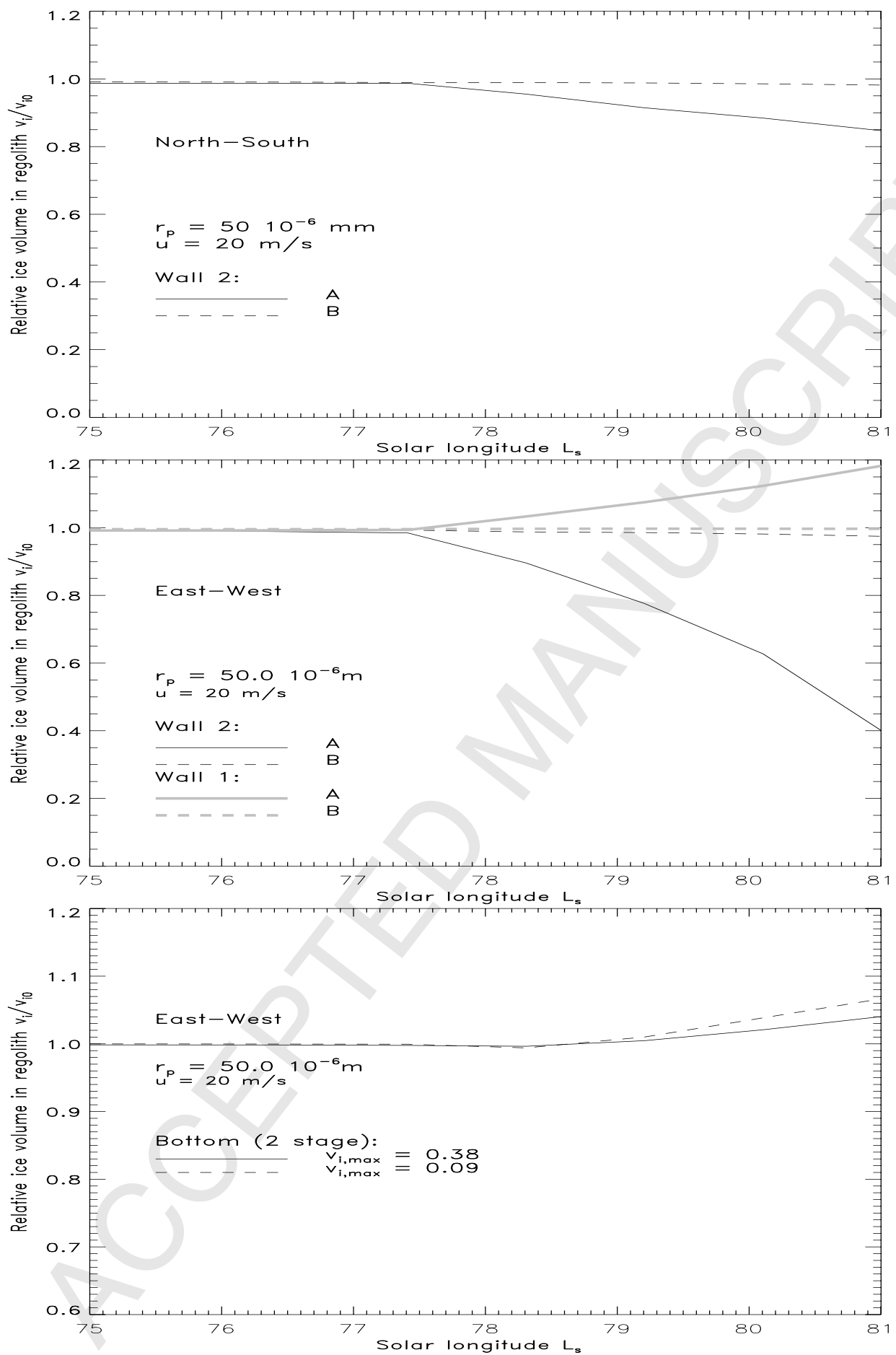

Fig. 8. Ice content in the regolith versus time. The results are: for the east wall (upper panel), the north and south walls (middle panel), and for the bottom (lower panel). The profiles are drawn for a point on the wall, $10 \mathrm{~cm}$ beneath the upper edge (point A); point in the regolith, $7 \mathrm{~cm}$ from $\mathrm{A}$ in the direction perpendicular to the wall (point B); and point on the bottom of the trough. The ice volume $v_{i, \max }$ is 0.38 (upper and middle panels), or 0.38 and 0.09 (lower panel). 


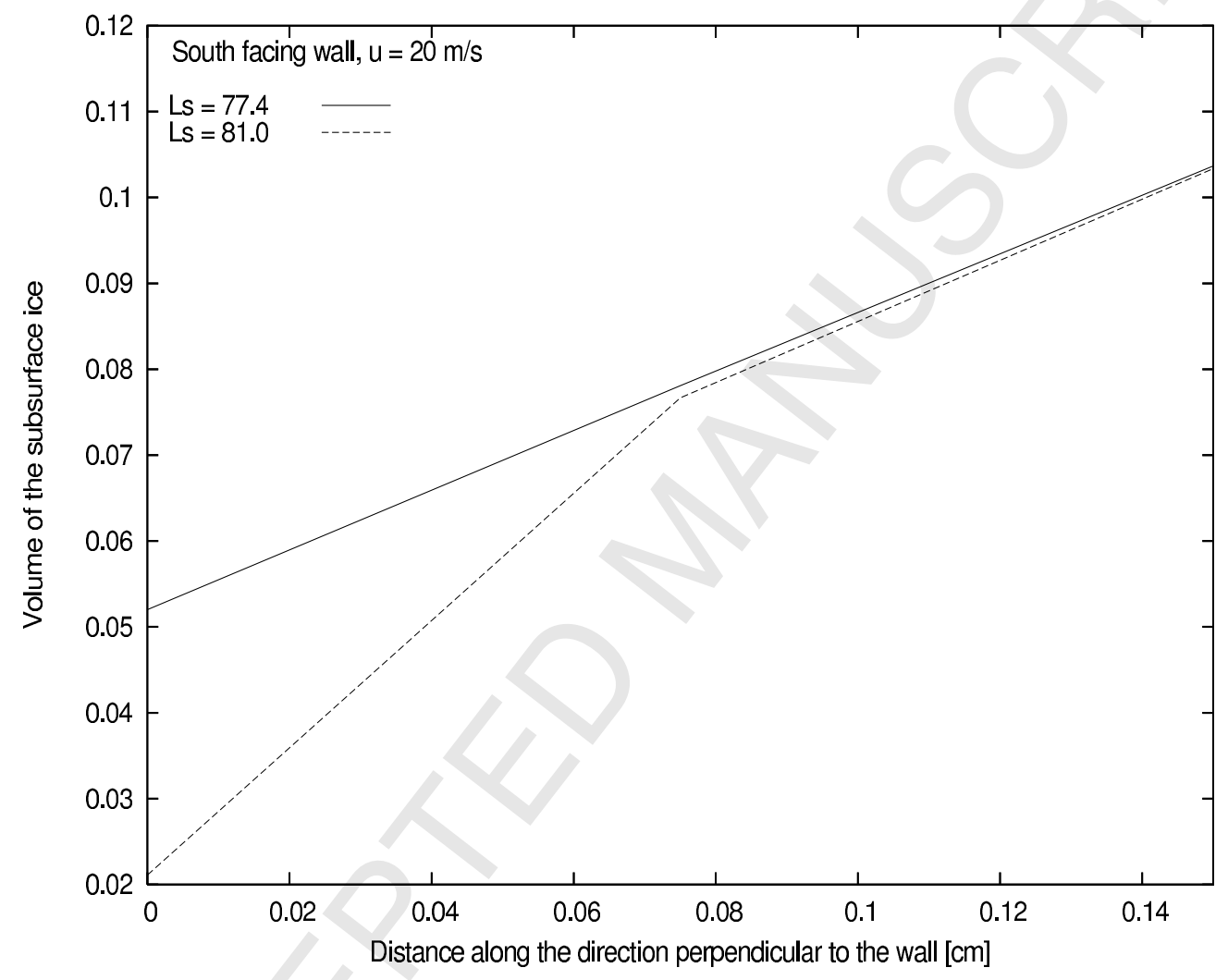

Fig. 9. Ice content in the regolith beneath the south facing wall. The profile is drawn versus distance perpendicular to the wall from the point A at the wall (see text). 